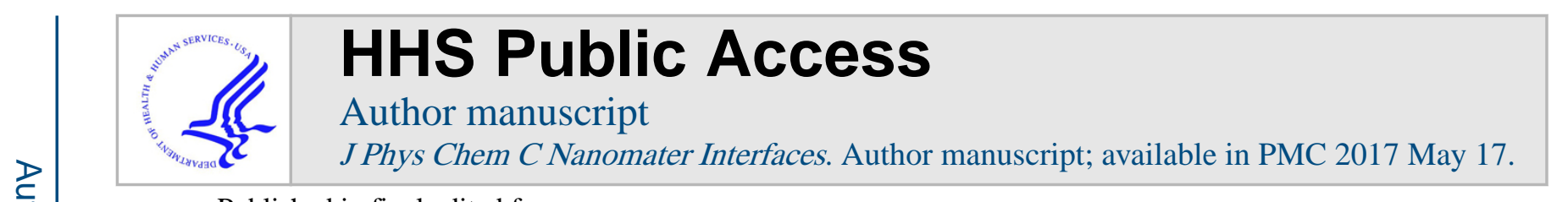

Published in final edited form as:

J Phys Chem C Nanomater Interfaces. 2016 May 17; 120(10): 5539-5548. doi:10.1021/acs.jpcc.5b12424.

\title{
Dehydrohalogenation Condensation Reaction of Phenylhydrazine with Cl-Terminated Si(111) Surfaces
}

\author{
Fei Gao and Andrew V. Teplyakov* \\ Department of Chemistry and Biochemistry, University of Delaware, Newark, Delaware 19716, \\ United States
}

\begin{abstract}
Formation of stable organic-inorganic contacts with silicon often requires oxygen- and carbonfree interfaces. Some of the general approaches to create such interfaces rely on the formation of a $\mathrm{Si}-\mathrm{N}$ bond. A reaction of dehydrohalogenation condensation of Cl-terminated $\mathrm{Si}(111)$ surface with phenylhydrazine is investigated as a means to introduce a simple function to the surface using a $\mathrm{NH}-\mathrm{NH}_{2}$ moiety as opposed to previously investigated approaches. The use of substituted hydrazine allows for the formation of a stable structure that is less strained compared to the previously investigated primary amines and leads to minimal surface oxidation. The process is confirmed by a combination of infrared studies, X-ray photoelectron spectroscopy, and time-offlight secondary ion mass spectrometry investigations. Density functional theory is utilized to yield a plausible surface reaction mechanism and provide a set of experimental observables to compare with these data.
\end{abstract}

\section{Graphical abstract}

*Corresponding Author. Tel.: (302) 831-1969. andrewt@ udel.edu. ASSOCIATED CONTENT

Supporting Information

The Supporting Information is available free of charge on the ACS Publications website at DOI: 10.1021/acs.jpcc.5b12424.

Summary of infrared investigations and complete ref 49, parameters used to calculate surface coverages of nitrogen and chlorine from the XPS spectra based on the overlayer model, as well as all the computational models of the initial steps in the phenylhydrazine reaction with $\mathrm{Cl}-\mathrm{Si}(111)$ surface (PDF).

The authors declare no competing financial interest. 


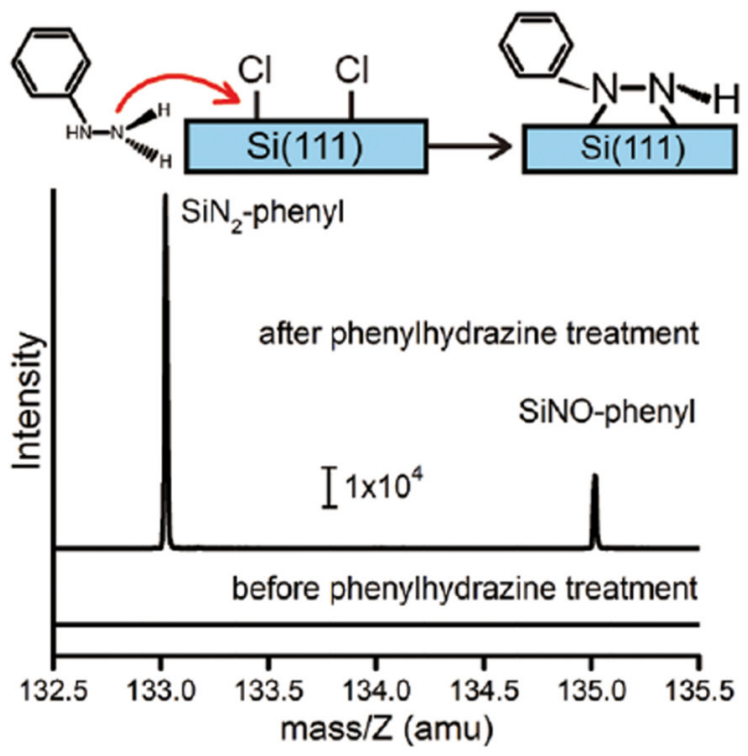

\section{INTRODUCTION}

Modification and organic functionalization of silicon surfaces has undergone tremendous growth within the last 40 years to benefit a number of applications including microelectronics, sensing, catalysis, and energy conversion. ${ }^{1-5}$

In order to produce the desired stable interfaces, silicon surfaces terminated with hydrogen or halogen are commonly used as starting points. Recent work on preparation and characterization of H-terminated ${ }^{6-11}$ and Cl-terminated ${ }^{12-16} \mathrm{Si}(100)$ and $\mathrm{Si}(111)$ single crystalline surfaces allows for a detailed understanding of the chemical processes with a truly molecular level precision. The functionalization step commonly includes the reactions of these modified silicon surfaces with appropriate organic reagents to produce stable organic monolayers that can, in turn, be further modified to yield nearly any chemical or biological functionality needed..$^{13,17-19}$

Although the majority of previous work targeted the formation of stable $\mathrm{Si}-\mathrm{C}$ bonds in hydrosilylation processes, ${ }^{20,21}$ more recently, substantial attention has been directed to avoid the presence of both carbon and oxygen directly at the interface with silicon. Considerable efforts have been focused on stable organic-inorganic interfaces on silicon with the help of $\mathrm{Si}-\mathrm{N}$ bonds. Thermodynamic stability and chemical versatility of such interfaces drove the initial investigations of ammonia, ${ }^{13,17,19,22-26}$ amines, ${ }^{27-29}$ nitro- and nitrosocompounds, ${ }^{30-33}$ as well as azides, ${ }^{34,35}$ with clean silicon single crystalline surfaces in vacuum toward more practical, cheap, and robust reactions of the same compounds with $\mathrm{H}$ or Cl-terminated silicon surfaces by wet chemistry methods. ${ }^{13,30,36-38}$ Tian et al. ${ }^{27}$ established a strategy to prepare a carbon- and oxygen-free monolayer on $\mathrm{Si}(111)$ surface terminated predominantly with $\mathrm{Si}-\mathrm{NH}-\mathrm{Si}$ functionality based on chlorination of the $\mathrm{H}$ terminated $\mathrm{Si}(111)$ surface, followed by the room temperature ammonia treatment with $\mathrm{NH}_{3}$-saturated tetrahydrofuran (THF). More recently, carbonand oxygen-free $\mathrm{Si}(111)$ 
surface terminated mostly with $\mathrm{Si}-\mathrm{NH}-\mathrm{NH}-\mathrm{Si}$ functionality was prepared in a similar reaction with anhydrous hydrazine at $35{ }^{\circ} \mathrm{C} .{ }^{28}$ The amines have been used in reactions with Cl-terminated silicon to introduce a variety of functionalities; $8,14-16,27-29,39$ however, hydrazine attachment presents a unique opportunity to yield the desired function, as will be demonstrated below.

Among the possible functional groups, the phenyl ring can be used as a good test-probe for surface reactions from a fundamental standpoint. The aromatic ring presents a nice target for spectroscopic characterization and quantitative analysis. ${ }^{29}$ Compared to unfunctionalized hydrazine, phenylhydrazine is more stable and easier to handle. At the same time, phenylbased organic monolayers possess a number of attractive properties, including their resistance to surface oxidation. ${ }^{40,41}$ In other words, this substituent can be used to tune chemical, mechanical, and electronic properties of a semiconductor surface.

This paper aims at a well-defined surface of silicon functionalized with phenylhydrazine to produce an oxygen-free platform for further investigation. A phenylhydrazine-functionalized $\mathrm{Si}(111)$ sample is obtained from a $\mathrm{Cl}-\mathrm{Si}(111)$ surface with phenylhydrazine at $35-38{ }^{\circ} \mathrm{C}$ under a $\mathrm{N}_{2}$ atmosphere. A schematic comparison of the main proposed products for reactions of ammonia, hydrazine, and phenylhydrazine is provided in Figure 1. This type of reaction involves $\mathrm{HCl}$ elimination and the formation of new $\mathrm{N}-\mathrm{Si}$ bonds; thus, they can serve as examples of dehydrohalogenation condensation process.

To confirm the presence of $\mathrm{Si}-\mathrm{N}$ bonds following this procedure and to establish the structures of surface species produced, every step of modification was followed by Fouriertransform infrared spectroscopy (FTIR), X-ray photoelectron spectroscopy (XPS), and timeof-flight secondary ion mass spectrometry (ToF-SIMS). Density functional theory (DFT) calculations were performed to propose a plausible mechanism of surface reaction and to produce a set of appropriate spectroscopic observables, including vibrational spectra and core-level energies, to compare with the results of experimental studies.

\section{EXPERIMENTAL SECTION}

\subsection{Materials}

n-Type double-side polished $\mathrm{Si}(111)$ wafers (Virginia Semiconductor, $>0.1 \Omega \cdot \mathrm{cm}$ resistivity, $500 \mu \mathrm{m}$ thickness) were used as substrates. All chemicals were reagent grade or as indicated: nitrogen (Praxair, boiled off from liquid nitrogen), argon (Keen Compressed Gas, research purity), hydrogen peroxide (Fisher, $30 \%$ certified ACS grade), ammonium hydroxide (Fisher, 29\% certified ACS plus grade), hydrochloric acid (Fisher, 37.3\% certified ACS grade), buffer-HF improved (Transene Company, Inc.), chlorobenzene (Acros, $99+\%), \mathrm{PCl}_{5}$

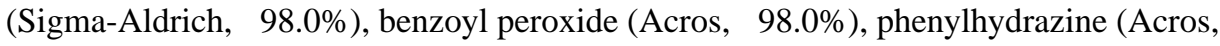
97\%), and THF (Fisher, distilled from Na/benzophenone). The deionized water used to rinse the surfaces and containers was from a first-generation Milli-Q water system (Millipore) with $18 \mathrm{M} \Omega \cdot \mathrm{cm}$ resistivity. 


\subsection{Experimental Details}

2.2.1. Preparation of Hydrogen-Terminated Si(111) Surface-The hydrogenmodified $\mathrm{Si}(111)$ surface was prepared by a modified RCA cleaning procedure. ${ }^{42-44}$ The Teflon beakers and $\mathrm{Si}(111)$ wafers were cleaned for 30 and $10 \mathrm{~min}$, respectively, in SC-1 solution, which is freshly prepared by mixing deionized water, hydrogen peroxide, and ammonium hydroxide (volume ratio $4: 1: 1$ ) in an $80^{\circ} \mathrm{C}$ water bath. After rinsing with deionized water, the clean wafers were etched in HF buffer solution for 2 min and rinsed again with deionized water. Then, the wafers were placed in SC-2 solution that was freshly prepared from deionized water, hydrogen peroxide, and hydrochloric acid (volume ratio 4:1:1) for 10 min to grow a silicon oxide layer. After that, the rinsed silicon wafers were etched in HF buffer solution again for $1 \mathrm{~min}$, followed by a 6 min etching process in ammonium fluoride solution to form a well-ordered hydrogen-terminated $\mathrm{Si}(111)$ surface, as confirmed by a sharp $2083 \mathrm{~cm}^{-1}$ peak of Si-H species in the infrared spectra, as described in detail below.

2.2.2. Preparation of Chlorine-Terminated Si(111) Surface-A well-established procedure ${ }^{16}$ was used to produce a chlorine-terminated $\mathrm{Si}(111)$ surface by reacting the $\mathrm{H}$ terminated $\mathrm{Si}(111)$ crystal with phosphorus pentachloride powder dissolved in chlorobenzene solvent to form a $\mathrm{PCl}_{5}$ solution, with trace amount of benzoyl peroxide added as a reaction initiator. This solution was purged with nitrogen gas for at least $30 \mathrm{~min}$ to remove gaseous impurities. A freshly generated hydrogen-terminated $\mathrm{Si}(111)$ wafer was placed into this solution on an oil bath at $110{ }^{\circ} \mathrm{C}$ for $1 \mathrm{~h}$ to prepare a stable chlorineterminated $\mathrm{Si}(111)$ sample. Freshly produced samples were kept under freshly distilled THF.

\subsubsection{Reaction of Phenylhydrazine with Chlorine-Terminated Si(111) Surface-}

The freshly prepared chlorine-terminated $\mathrm{Si}(111)$ sample was transferred into a clean Schlenck flask containing phenylhydrazine solution bubbled with Ar for $30 \mathrm{~min}$ and was placed in an oil bath at room temperature. The phenylhydrazine solution was prepared by mixing phenylhydrazine and THF (volume ratio 1:2). The chlorine-terminated silicon wafer was stirred in the phenylhydrazine solution under $\mathrm{N}_{2}$ at $35-38{ }^{\circ} \mathrm{C}$ for $1 \mathrm{~h}$ to form a phenylhydrazine-reacted $\operatorname{Si}(111)$ surface. After the reaction, the phenylhydrazine-reacted $\mathrm{Si}(111)$ surface was rinsed with dry methanol, dried with Ar gas, and kept under fresh THF.

\subsection{Characterization Methods}

2.3.1. Fourier-Transform Infrared Spectroscopy (FTIR)—A Nicolet Magna-IR 560 spectrometer with a liquid nitrogen-cooled MCT detector was used to collect transmission infrared spectra in the range $4000-650 \mathrm{~cm}^{-1}$ with an incident angle of $60^{\circ}$ with respect to the incoming infrared beam. All the spectra were collected with 512 scans per spectrum, and a resolution of $8 \mathrm{~cm}^{-1}$ was used. The native oxide-covered and hydrogen-terminated $\mathrm{Si}(111)$ wafers were used as backgrounds, as indicated below.

2.3.2. X-ray Photoelectron Spectroscopy (XPS) - XPS studies were performed on a K-Alpha ${ }^{+}$X-ray Photoelectron Spectrometer (XPS) System from Thermo Scientific. The Al Ka X-ray source $(h v=1486.6 \mathrm{eV})$ at a $35.3^{\circ}$ takeoff angle with respect to the analyzer was used for all the XPS experiments. The survey spectra were collected over the energy range 
of $0-1000 \mathrm{eV}$. The high-resolution spectra for spectral regions corresponding to $\mathrm{Si} 2 \mathrm{p}, \mathrm{O} 1 \mathrm{~s}$, $\mathrm{Cl} 2 \mathrm{p}$, and $\mathrm{N} 1 \mathrm{~s}$ were collected over the range of 20 at $0.1 \mathrm{eV} / \mathrm{step}$, and the pass energy of $58.7 \mathrm{eV}$ was used. All the raw data were analyzed by CasaXPS software, with all peak positions and relative sensitivity factors calibrated to the most intense $\mathrm{C} 1 \mathrm{~s}$ peak, which was set to have the binding energy of $284.6 \mathrm{eV} \cdot{ }^{16,45-47}$

To quantify surface coverages of chlorine and nitrogen, an overlayer model was used with the following assumptions: ${ }^{15,45,48}$ (1) chlorine- or nitrogen-containing groups are the closest to the silicon substrate, and the adventitious hydrocarbon and oxygen layer is on top of the chlorine or nitrogen overlayer; (2) all the chlorine or nitrogen atoms in the overlayer are in the solid state.

The equivalent monolayer coverage of an overlayer species was calculated according to the procedure described in detail previously for a carefully calibrated set of parameters. ${ }^{27-30}$ The chlorine coverage corresponding to one complete monolayer was taken as $100 \%$, and the relative coverages of chlorine- and nitrogen-containing surface species during the course of reaction were determined by comparison with the initial coverage and using the appropriate sensitivity factors, as summarized in Table 1 of the Supporting Information.

2.3.3. Time-of-Flight Secondary lon Mass Spectrometry (ToF-SIMS)—A ToFSIMS instrument (ToF-SIMS IV, ION-TOF, Münster, Germany) was used to obtain static negative and positive spectra with a $25 \mathrm{keV}$ monoisotopic $\mathrm{Bi}_{3}{ }^{+}$ion beam. The spectra were collected with a mass resolution of $m / \Delta m=9000$ and image resolution of $128 \times 128$ pixels, the area of analysis was $100 \times 100 \mu \mathrm{m}^{2}$ over 50 scans. All primary bismuth ion fluences were below the threshold of $1 \times 10^{13} \mathrm{ions} / \mathrm{cm}^{2}$ for static SIMS. Both positive- and negativeion spectra were collected, but only negative ion spectra are provided below, as they were the most informative. The calibration of ToF-SIMS data was performed using ION-TOF measurement explorer software (version 6.3). The calibration masses were $\mathrm{H}^{+}, \mathrm{H}_{2}{ }^{+}, \mathrm{H}_{3}{ }^{+}$, $\mathrm{C}^{+}, \mathrm{CH}^{+}, \mathrm{CH}_{2}^{+}, \mathrm{CH}_{3}{ }^{+}, \mathrm{C}_{2} \mathrm{H}_{3}{ }^{+}, \mathrm{C}_{3} \mathrm{H}_{5}^{+}, \mathrm{C}_{4} \mathrm{H}_{7}+\mathrm{C}_{5} \mathrm{H}_{5}^{+}, \mathrm{C}_{6} \mathrm{H}_{5}^{+}$, and $\mathrm{C}_{7} \mathrm{H}_{7}+$ in positive mode and $\mathrm{H}^{-}, \mathrm{H}_{2}^{-}, \mathrm{C}^{-}, \mathrm{CH}^{-}, \mathrm{CH}_{2}^{-}, \mathrm{CH}_{3}{ }^{-}, \mathrm{C}_{2}^{-}, \mathrm{C}_{2} \mathrm{H}^{-}, \mathrm{C}_{3}{ }^{-}, \mathrm{C}_{4}^{-}, \mathrm{C}_{5}^{-}, \mathrm{C}_{6}{ }^{-}, \mathrm{C}_{7}^{-}$, and $\mathrm{C}_{8}{ }^{-}$in negative mode.

2.3.4. Computational Details-Density Function Theory (DFT) calculations were performed with the Gaussian 09 suite of programs ${ }^{49}$ utilizing the B3LYP functional and 6-311+G-(d,p) basis set. ${ }^{50-53} \mathrm{~A} \mathrm{Si}_{17} \mathrm{H}_{24}$ cluster model, which represents two neighboring top silicon atoms on a $\mathrm{Si}(111)$ surface terminated with hydrogen or chlorine was used. The bottom three layers in this $\mathrm{Si}_{17} \mathrm{H}_{24}$ cluster model were fixed at their bulk positions in DFT calculations to avoid unrealistic distortions. The $\mathrm{N} 1 \mathrm{~s}$ core-level energy was predicted using Koopmans' theorem on the basis of this $\mathrm{Si}_{17} \mathrm{H}_{24}$ cluster model, and the correction factor to the predicted core-level energy for $\mathrm{N} 1 \mathrm{~s}$ was $8.76 \mathrm{eV}$ based on our previous investigations. ${ }^{12,54}$ The infrared frequencies were scaled by a common scaling factor of 0.965 , which has proven to be successful in a number of the previous investigations of organic adsorbates on silicon. ${ }^{27-30}$ All the models used in this publication are presented in the Supporting Information. 


\section{RESULTS AND DISCUSSION}

\subsection{Confirmation of Phenylhydrazine Reaction with Cl-Si(111) Surface by Infrared Spectroscopy}

In order to confirm the reaction of phenylhydrazine with a $\mathrm{Cl}-\mathrm{Si}(111)$ surface and to possibly identify the products of this reaction, infrared spectra of the resulting surface were interrogated. Figure 2 summarizes the most informative spectral region confirming the presence of $\mathrm{C}-\mathrm{H}$ and $\mathrm{N}-\mathrm{H}$ containing chemical groups following the reaction. The $\mathrm{N}-\mathrm{H}$ stretching vibrations corresponding to $-\mathrm{NH}_{X}$ species are recorded around $3328 \mathrm{~cm}^{-1}$, and an obvious feature just above $3000 \mathrm{~cm}^{-1}$ corresponding to the $\mathrm{C}-\mathrm{H}$ stretching of the phenyl ring is clearly observed. Even based on these results alone, it is possible to infer that the phenyl ring remains intact following the reaction of phenylhydrazine with a $\mathrm{Cl}-\mathrm{Si}(111)$ surface. Otherwise, the $\mathrm{C}-\mathrm{H}$ vibrations corresponding to the rehybridized species containing $\mathrm{sp}^{2}$ and $\mathrm{sp}^{3}$ carbon would be observed below $3000 \mathrm{~cm}^{-1}$. ${ }^{55-58}$ In order to attempt identification of the surface species more precisely, comparison of the experimental spectra with the computationally predicted vibrational signatures of the proposed surface species is needed, as also summarized in Figure 2. The possible surface models of the resulting species with a restriction that they must maintain the intact phenyl ring and possess some $\mathrm{N}-\mathrm{H}$ bonds include all the species presented in the figure. However, it appears that based on these predictions alone it is impossible to distinguish them. Nevertheless, the fact that the phenyl ring remains intact and that the surface species possess $\mathrm{N}-\mathrm{H}$ bonds will be important for further studies outlined below. The infrared studies of the $\mathrm{Si}-\mathrm{H}$ region following the phenylhydrazine reaction with the $\mathrm{Cl}-\mathrm{Si}(111)$ surface are presented for reference in Figure S1 in the Supporting Information. The rest of the spectral features are summarized in Table 1. Although the computational study suggests that there may be some subtle spectroscopic differences between the two possible models shown in Figure 2, especially within the fingerprint region, distinguishing them based on the experimental spectra collected in this study is not feasible, as the spectra are complicated by the effect of partial oxidation during the collection time on the absorption features.

\subsection{X-ray Photoelectron Spectroscopy Investigation of the Extent of the Reaction and Additional Information on Surface Species Formed during Phenyl-shydrazine Interaction with the $\mathrm{Cl}-\mathrm{Si}(111)$}

Surface. In this study, a number of important conclusions can be reached based on XPS investigation. The first question that can be answered by this surface analytical technique is the quality of the surface with respect to surface oxidation. The analysis of the Si $2 p$ spectra presented in Figure 3 reveals that no silicon surface oxidation was observed during the experimental procedure for obtaining H-terminated and Cl-terminated $\mathrm{Si}(111)$ substrates, as shown in spectra (a) and (b). The dashed line in Figure 3 indicates the expected position for the XPS feature corresponding to $\mathrm{SiO}_{X}$ at approximately $103 \mathrm{eV} \cdot{ }^{16,27,28,64-69} \mathrm{~A} \mathrm{Si} 2 \mathrm{p}$ spectrum obtained following phenylhydrazine treatment exhibits a very minor feature at $102.2 \mathrm{eV}$ in addition to the typical signature of the clean silicon surface, and as reaction time increases from $1 \mathrm{~h}$ in Figure 3c to $3.5 \mathrm{~h}$ in Figure 3f, this minor feature increases in intensity and also shifts to the higher energy. Previous investigations of the feature observed at 102.2 $\mathrm{eV}$ suggest that it is most likely a signature of surface nitride ${ }^{27,28,70}$ formed at the surface 
defect sites. The position of this feature is clearly different from the $103 \mathrm{eV}$ peak corresponding to $\mathrm{SiO}_{X} \cdot{ }^{64}$ Prolonged exposure to ambient conditions does result in surface oxidation. The signs of this oxidation are definitely noticeable in Figure $3 \mathrm{f}$ for a $3.5 \mathrm{~h}$ contact time with phenylhydrazine, suggesting that even in a nearly oxygen-free atmosphere, surface oxide is formed if the reaction time is increased substantially. ${ }^{29}$

Although silicon surface oxidation does not seem to pose substantial problems to the proposed surface modification approach at relatively short reaction times, it is important to understand how effective chlorine removal is during this process. Representative $\mathrm{Cl} 2 \mathrm{p}$ spectra of the $\mathrm{Si}(111)$ surface before and after phenylhydrazine modification are shown in Figure 4. As expected, no chlorine is present on the H-terminated $\mathrm{Si}(111)$ shown in Figure 4a; the signature of this element appears only following silicon modification with $\mathrm{PCl}_{5}$. After this modification step, only one type of chlorine-containing species is observed on the surface, as shown in Figure $4 \mathrm{~b}$. Based on the coverage analysis following the overlayer model applied to this system according to Lewis et al., ${ }^{14-16}$ the chlorine coverage observed in this experiment is consistent with the previously reported data for $~ 99 \%$ of a monolayer. ${ }^{27,28}$ Following the $1 \mathrm{~h}$ reaction of the $\mathrm{Cl}-\mathrm{Si}(111)$ surface with phenylhydrazine shown in Figure $4 \mathrm{c}$, the amount of surface chlorine is drastically reduced and the concentration of this element on a surface quickly approaches zero at longer reaction times shown in Figure 4d-f.

Figure 5 presents a summary of the $\mathrm{N} 1 \mathrm{~s}$ investigations for the reaction of phenylhydrazine with a $\mathrm{Cl}-\mathrm{Si}(111)$ surface. Figure $5 \mathrm{a}$ and $\mathrm{b}$ show that no nitrogen is present on $\mathrm{H}$-terminated or Cl-terminated $\mathrm{Si}(111)$, respectively. Figure 5c clearly shows a dominant feature at 399.7 $\mathrm{eV}$. The binding energy that corresponds to this observed feature is compared to the selected results of the DFT investigation of the models presented in Figure 5. The predictions of the $\mathrm{N}$ 1s binding energies for the main expected possible geometry, Si-N-NH(phenyl)-Si, on the surface following phenylhydrazine treatment are 399.44 and $399.00 \mathrm{eV}$. Another possible $\mathrm{NH}_{X}$ functionality on the surface, Si-NH-NH-phenyl, is predicted to exhibit peaks at 398.73, 399.04, 399.25, and $399.96 \mathrm{eV}$ (for a model containing two Si-NH-NH-phenyl species on neighboring surface sites). The third possible structure for $\mathrm{NH}_{X}$ species on the surface, $\mathrm{Si}$ $\mathrm{N}(\mathrm{Si})$-phenyl, is predicted to exhibit a peak at $398.73 \mathrm{eV}$.

Based on the comparison of experimental and computationally predicted spectra, it again appears that all the proposed species would have spectral signatures consistent with the experiment. It is important to highlight that the main feature observed experimentally is very different in energy from those that would originate from $\mathrm{N}-\mathrm{Si}$ or $\mathrm{N}-\mathrm{N}$ bond oxidation ${ }^{13,27,28}$ or the formation of a hydrazine salt. ${ }^{28}$

The minor peak observed at $397.7 \mathrm{eV}$ does increase with the reaction time. Based on the previous studies, it is likely a signature of a minor channel of a hydrazine reaction $-\mathrm{N}-\mathrm{N}$ dissociation. This assignment is supported by comparing the observed energy with those reported for hydrazine and ammonia reacting with a $\mathrm{Cl}-\mathrm{Si}(111)$ surface $^{27,28}$ and by an illustration of a possible position for such a species in Figure 5. 
By applying the quantitative analysis described by Lewis et al., ${ }^{15,16,45}$ the ratio of the $\mathrm{N} 1 \mathrm{~s}$ feature and $\mathrm{Si} 2 \mathrm{p}$ feature on the phenylhydrazine-treated surface can be calibrated with the corresponding ratio of the $\mathrm{Cl} 2 \mathrm{p}$ feature and $\mathrm{Si} 2 \mathrm{p}$ feature on the Cl-terminated $\mathrm{Si}(111)$ (where $\sim 99 \%$ of the surface is covered with $\mathrm{Cl}$ atoms). This procedure yields a nitrogen coverage of $21 \pm 5 \%$ following $1.5 \mathrm{~h}$ contact time.

The quantitative results of apparent relative surface coverages of $\mathrm{N}$ and $\mathrm{Cl}$ are summarized in Figure 6. The trends shown in this figure reveal that the apparent coverage of $\mathrm{N}$ increases up to $2.5 \mathrm{~h}$ of the reaction time and decreases at longer exposure. The decrease is likely caused by surface oxidation observed at very long reaction times even in the controlled conditions used in this work. The apparent coverage of $\mathrm{Cl}$ decreases quickly and approaches zero for reaction times higher than $1.5 \mathrm{~h}$. The analysis of these trends suggests that chlorine removal is a relatively easy process, which will be further supported by computational studies. However, it is apparent that the reaction becomes very complicated and is affected substantially by surface reconstruction and surface oxidation processes for contact times longer than $2.5 \mathrm{~h}$.

\subsection{Identification of Surface Species Formed During Phenylhydrazine Interaction with the Cl-Si(111) Surface by ToF-SIMS}

The infrared spectroscopy and XPS investigations reported above help rule out the presence of certain surface species as a result of the reaction of phenylhydrazine with a $\mathrm{Cl}-\mathrm{Si}(111)$ surface. A comparison with selected DFT models also suggested that their expected vibrational and XPS signatures are consistent with the recorded experimental spectra. However, based on these studies alone, it is practically impossible to identify the actual species present on a surface following this reaction. In order to further identify the species present on a surface following the phenylhydrazine reaction, ToF-SIMS traces were recorded before and after surface modification. Figure 7 presents a summary of the most relevant spectral ranges studied by this surface analytical technique.

Negative ion ToF-SIMS spectra are used for plots a-c in Figure 7, which confirm that only following phenylhydrazine treatment, are the signatures for surface bound phenylhydrazine reaction products observed. Specifically, negative ion $\mathrm{m} / \mathrm{z}$ ranges of 55.5-58.5, 132.5-135.5, and 160.5-163.5 are summarized in these plots. Following the phenylhydrazine treatment, the $\left[\mathrm{Si}-\mathrm{N}_{2} \mathrm{H}\right]^{-}$fragment is clearly present and corresponds to the highest intensity feature in Figure 7a. Generally, ToF-SIMS cannot be used for a quantitative comparison of different but closely related surface species; however, if the ionization cross sections of the $\left[\mathrm{Si}_{-} \mathrm{N}_{2} \mathrm{H}\right]^{-}$ and $\left[\mathrm{Si}-\mathrm{N}_{2} \mathrm{H}_{2}\right]^{-}$species are similar, the intensity difference between the two corresponding peaks in Figure 7a suggests that most of them are originated from $\mathrm{Si}-\mathrm{N}_{2} \mathrm{H}-\mathrm{Si}$ surface fragments and not from the $\mathrm{Si}-\mathrm{N}_{2} \mathrm{H}_{2}$ surface species. There are $\left[\mathrm{Si}-\mathrm{N}_{2}-\right.$ phenyl] ${ }^{-}$and [Si-NOphenyl $]^{-}$species observed to be present in Figure $7 \mathrm{~b}$. The oxidized species are generally observed to be present in this experimental setup since oxygen gas is always present in the background, albeit in very small quantities. Signatures of $\left[\mathrm{Si}_{2}-\mathrm{N}_{2} \text {-phenyl] }\right]^{-},\left[\mathrm{Si}_{2}-\mathrm{N}_{2} \mathrm{H}-\right.$ phenyl $]^{-}$, and $\left[\mathrm{Si}_{2}-\mathrm{NO} \text {-phenyl }\right]^{-}$species are presented in Figure $7 \mathrm{c}$. To clarify and confirm the observed signatures, a zoom-in of [Si-NO-phenyl] ${ }^{-}$feature at $135.02 \mathrm{~m} / \mathrm{z}$ is presented in Figure $8 \mathrm{a}$, with the vertical line indicating the expected position of the $\left[\mathrm{Si}-\mathrm{N}_{2} \mathrm{H}_{2} \text {-phenyl] }\right]^{-}$ 
species, which is clearly absent. This comparison rules out the structure of [Si-NH-NHphenyl] $^{-}$as a signature of a dominant surface species. Similarly, the zoom-in in Figure 8b clearly shows a peak at 162.98 corresponding to the minor oxidized [ $\mathrm{Si}_{2}-\mathrm{NO}$-phenyl] ${ }^{-}$ species and not the $\left[\mathrm{Si}_{2}-\mathrm{N}_{2} \mathrm{H}_{2} \text {-phenyl] }\right]^{-}$group, whose expected position is also indicated by a vertical line.

Together with the infrared and XPS results described above, the ToF-SIMS studies zero in on a dominant surface species. Although infrared and XPS results could not identify this species unambiguously, they confirmed the presence of the intact phenyl ring, the absence of major surface oxidation, and the relatively low coverage of nitrogen even at the optimal set of conditions. ToF-SIMS confirmed that the $\mathrm{N}-\mathrm{N}$ bond is intact in the majority surface species and that the Si-NH-N(phenyl)-Si structure is indeed the dominant one.

\subsection{Computational Explanation of the Initial Steps of the Surface Reaction Mechanism for Phenylhydrazine Interaction with a $\mathrm{Cl}-\mathrm{Si}(111)$ Surface}

The proposed mechanism of the initial steps of phenylhydrazine interaction with a $\mathrm{Cl}-$ $\mathrm{Si}(111)$ surface is depicted in Figure 9. The initial adsorption of phenylhydrazine on a $\mathrm{Cl}-$ $\mathrm{Si}(111)$ surface is a slightly exothermic process, and the first reaction step is endothermic, with a very modest reaction barrier. The proposed second step leads to a much more endothermic product; however, it is overall consistent with the previously interrogated reactions of ammonia and unfunctionalized hydrazine on the $\mathrm{Cl}-\mathrm{Si}(111)$ surface. It is likely that the endothermicity of this reaction is greatly moderated by a surface reconstruction and also by the fact that the $\mathrm{HCl}$ molecule released as a consequence of the reaction is bound to a phenylhydrazine molecule since phenylhydrazine is present in excess in the reaction mixture. The stability of the resulting product is similar for this model to the stability of the unfunctionalized hydrazine in a similar reaction. ${ }^{28}$ However, the different stabilities of the final salts $\left(\mathrm{NH}_{2}-\mathrm{NH}_{3} \mathrm{Cl}\right.$ vs $\left.\mathrm{Ph}-\mathrm{NH}-\mathrm{NH}_{3} \mathrm{Cl}\right)$ will definitely affect the overall thermodynamics of the process. What makes the process involving phenylhydrazine different is the resulting efficiency of the process, with only approximately a quarter of surface silicon atoms connected to a nitrogen atom of the incoming phenylhydrazine molecule. The most straightforward explanation for such a difference is in thebulkiness of phenylhydrazine. Specifically, if the structure of the first step product (where a single $\mathrm{Si}-\mathrm{N}$ linkage is formed and a single $\mathrm{HCl}$ molecule is released) is considered carefully, it becomes apparent that the substituent phenyl ring is hindering the possible approach of another phenylhydrazine molecule to engage in a chemical interaction with the surface. Once the reaction goes to completion, with both nitrogen atoms of the phenylhydrazine forming Si-N linkers and two $\mathrm{HCl}$ molecules released, this hindrance does not disappear and, in fact, becomes even more pronounced. Further investigations of the surface reconstruction, consistent with a rather low surface coverage of nitrogen and, at the same time, essentially absent surface oxidation that could potentially stabilize this reconstruction, are necessary.

\section{CONCLUSIONS}

The work described in this manuscript attempts to understand a complex process of phenylhydrazine interaction with a $\mathrm{Cl}-\mathrm{Si}(111)$ surface to introduce a chemical functionality 
based on a dehydrohalogenation condensation process. The ultimate goal of this approach would be to introduce high coverage of a target functionality based exclusively on $\mathrm{Si}-\mathrm{N}$ linkers and without surface oxidation. The infrared investigation confirms the reaction and also confirms that the introduced functionality remains intact following the modification procedure. XPS studies are consistent with the proposed surface species and also confirm the absence of substantial surface oxidation unless the reaction time exceeds $2.5 \mathrm{~h}$. ToF-SIMS allows for identification of the majority species formed and the DFT studies offer a possible mechanism for the initial interaction steps for phenylhydrazine. However, an increase of surface coverage of functionalized hydrazines or at least the reasons behind such a high stability of the modified surface with respect to oxidation, likely a stable reconstruction, in ambient conditions have to be understood in further studies.

\section{Supplementary Material}

Refer to Web version on PubMed Central for supplementary material.

\section{Acknowledgments}

Acknowledgment is made to the donors of the Petroleum Research Fund, administered by the American Chemical Society, for partial support of this research. This work was also supported by the National Science Foundation (CHE 1057374). The authors acknowledge the NSF $(9724307 ; 1428149)$ and the NIH NIGMS COBRE program (P30-GM110758) for partial support of activities in the University of Delaware Surface Analysis Facility. The authors would like to thank Mr. Zachary Voras for help with collecting ToF-SIMS spectra at the Surface Analysis Facility, Department of Chemistry and Biochemistry, University of Delaware.

\section{REFERENCES}

1. Bent SF, Teplyakov AV. Semiconductor Surface Functionalization for Advances in Electronics, Energy Conversion, and Dynamic Systems. J. Vac. Sci. Technol., A. 2013; 31:050810-1-05081012.

2. Liu Z, Amiridis MD. Quantitative FT-IRRAS Spectroscopic Studies of the Interaction of Avidin with Biotin on Functionalized Quartz Surfaces. J. Phys. Chem. B. 2005; 109:16866-16872. [PubMed: 16853146]

3. Margelefsky E, Zeidan R, Davis M. Cooperative Catalysis by Silica-Supported Organic Functional Groups. Chem. Soc. Rev. 2008; 37:1118-1126. [PubMed: 18497925]

4. Zhao J, Wang A, Green MA. 24.5\% Efficiency Silicon Pert Cells on Mcz Substrates and 24.7\% Efficiency Perl Cells on Fz Substrates. Prog. Photovoltaics. 1999; 7:471-474.

5. Stutz H. Protein Attachment onto Silica Surfaces-a Survey of Molecular Fundamentals, Resulting Effects and Novel Preventive Strategies in Ce. Electrophoresis. 2009; 30:2032-2061. [PubMed: 19582707]

6. Clark IT, Aldinger BS, Gupta A, Hines MA. Aqueous Etching Produces Si(100) Surfaces of nearAtomic Flatness: Strain Minimization Does Not Predict Surface Morphology. J. Phys. Chem. C. 2010; 114:423-428.

7. Aldinger BS, Hines MA. Si(100) Etching in Aqueous Fluoride Solutions: Parallel Etching Reactions Lead to Ph-Dependent Nanohillock Formation or Atomically Flat Surfaces. J. Phys. Chem. C. 2012; 116:21499-21507.

8. Chopra TP, Longo RC, Cho K, Halls MD, Thissen P, Chabal YJ. Ethylenediamine Grafting on Oxide-Free H-, 1/3 Ml F-, and Cl-Terminated Si(111) Surfaces. Chem. Mater. 2015; 27:6268-6281.

9. Michalak DJ, Amy SR, Aureau D, Dai M, Estève A, Chabal YJ. Nanopatterning Si(111) Surfaces as a Selective Surface-Chemistry Route. Nat. Mater. 2010; 9:266-271. [PubMed: 20062049]

10. Perrine KA, Teplyakov AV. Reactivity of Selectively Terminated Single Crystal Silicon Surfaces. Chem. Soc. Rev. 2010; 39:3256-3274. [PubMed: 20596551] 
11. Michalak DJ, Rivillon S, Chabal YJ, Estève A, Lewis NS. Infrared Spectroscopic Investigation of the Reaction of Hydrogen-Terminated, (111)-Oriented, Silicon Surfaces with Liquid Methanol. J. Phys. Chem. B. 2006; 110:20426-20434. [PubMed: 17034227]

12. Leftwich TR, Teplyakov AV. Calibration of Computationally Predicted N $1 s$ Binding Energies by Comparison with X-Ray Photoelectron Spectroscopy Measurements. J. Electron Spectrosc. Relat. Phenom. 2009; 175:31-40.

13. Tian F, Teplyakov AV. Silicon Surface Functionalization Targeting Si-N Linkages. Langmuir. 2013; 29:13-28. [PubMed: 23094599]

14. Webb LJ, Lewis NS. Comparison of the Electrical Properties and Chemical Stability of Crystalline Silicon(111) Surfaces Alkylated Using Grignard Reagents or Olefins with Lewis Acid Catalysts. J. Phys. Chem. B. 2003; 107:5404-5412.

15. Webb LJ, Nemanick EJ, Biteen JS, Knapp DW, Michalak DJ, Traub MC, Chan ASY, Brunschwig BS, Lewis NS. High-Resolution X-Ray Photoelectron Spectroscopic Studies of Alkylated Silicon(111) Surfaces. J. Phys. Chem. B. 2005; 109:3930-3937. [PubMed: 16851446]

16. Bansal A, Li XL, Yi SI, Weinberg WH, Lewis NS. Spectroscopic Studies of the Modification of Crystalline Si(111) Surfaces with Covalently-Attached Alkyl Chains Using a Chlorination/ Alkylation Method. J. Phys. Chem. B. 2001; 105:10266-10277.

17. Rodríguez-Reyes JCF, Teplyakov AV. Cooperative Nitrogen Insertion Processes: Thermal Transformation of NH3 on a Si(100) Surface. Phys. Rev. B: Condens. Matter Mater. Phys. 2007; 76:075348-1-075348-16.

18. Gangarapu S, Pujari SP, Alon H, Rijksen B, Sukenik CN, Zuilhof H. Effect of a-Heteroatoms on the Formation of Alkene-Derived Monolayers on H-Si(111): A Combined Experimental and Theoretical Study. Langmuir. 2015; 31:8318-8327. [PubMed: 26202750]

19. Rodríguez-Reyes JCF, Teplyakov AV. Role of Surface Strain in the Subsurface Migration of Adsorbates on Silicon. Phys. Rev. B: Condens. Matter Mater. Phys. 2008; 78:165314-1-16531414.

20. Buriak JM. Organometallic Chemistry on Silicon and Germanium Surfaces. Chem. Rev. 2002; 102:1271-1308. [PubMed: 11996538]

21. Pujari SP, Scheres L, Marcelis ATM, Zuilhof H. Covalent Surface Modification of Oxide Surfaces. Angew. Chem., Int. Ed. 2014; 53:6322-6356.

22. Widjaja Y, Musgrave CB. A Density Functional Theory Study of the Nonlocal Effects of NH3 Adsorption and Dissociation on Si(100)-(2×1). Surf. Sci. 2000; 469:9-20.

23. Widjaja Y, Mysinger MM, Musgrave CB. Ab Initio Study of Adsorption and Decomposition of $\mathrm{NH}_{3}$ on $\mathrm{Si}(100)-(2 \times 1)$. J. Phys. Chem. B. 2000; 104:2527-2533.

24. Kubler L, Bischoff JL, Bolmont D. General Comparison of the Surface Processes Involved in Nitridation of Si(100)-2 $\times 1$ by NH3, and in SiNx Film Deposition: A Photoemission Study. Phys. Rev. B: Condens. Matter Mater. Phys. 1988; 38:13113-13123.

25. Rangelov G, Stober J, Eisenhut B, Fauster T. $\mathrm{NH}_{3}$ and NO Interaction with $\mathrm{Si}(100)-(2 \times 1)$ Surfaces. Phys. Rev. B: Condens. Matter Mater. Phys. 1991; 44:1954-1957.

26. Perrine KA, Lin J-M, Teplyakov AV. Controlling the Formation of Metallic Nanoparticles on Functionalized Silicon Surfaces. J. Phys. Chem. C. 2012; 116:14431-14444.

27. Tian F, Taber DF, Teplyakov AV. NH-Termination of the Si(111) Surface by Wet Chemistry. J. Am. Chem. Soc. 2011; 133:20769-20777. [PubMed: 22081982]

28. Gao F, Teplyakov AV. Reaction of Hydrazine with a Chlorine-Terminated Si(111) Surface. J. Phys. Chem. C. 2014; 118:27998-28006.

29. Cui Y, Tian F, Gao F, Teplyakov AV. Building Organic Monolayers Based on Fluorinated Amines on the Si(111) Surface. J. Phys. Chem. C. 2014; 118:26721-26728.

30. Tian F, Cui Y, Teplyakov AV. Nitroxidation of H-Terminated Si(111) Surfaces with Nitrobenzene and Nitrosobenzene. J. Phys. Chem. C. 2014; 118:502-512.

31. Bocharov S, Mathauser AT, Teplyakov AV. Adsorption and Thermal Chemistry of Nitroethane on Si(100)-2 × 1. J. Phys. Chem. B. 2003; 107:7776-7782.

32. Bocharov S, Teplyakov AV. Adsorption, Ordering, and Chemistry of Nitrobenzene on Si(100)- $2 \times$ 1. Surf. Sci. 2004; 573:403-412. 
33. Méndez De Leo LP, Teplyakov AV. Nitro Group as a Means of Attaching Organic Molecules to Silicon: Nitrobenzene on Si(100)-2 × 1. J. Phys. Chem. B. 2006; 110:6899-6905. [PubMed: 16571000]

34. Bocharov S, Dmytrenko O, Méndez De Leo LP, Teplyakov AV. Azide Reactions for Controlling Clean Silicon Surface Chemistry: Benzylazide on Si(100)-2 × 1. J. Am. Chem. Soc. 2006; 128:9300-9301. [PubMed: 16848443]

35. Leftwich TR, Teplyakov AV. Cycloaddition Reactions of Phenylazide and Benzylazide on a Si(100)-2 × 1 Surface. J. Phys. Chem. C. 2008; 112:4297-4303.

36. Cao P, Xu K, Heath JR. Azidation of Silicon(111) Surfaces. J. Am. Chem. Soc. 2008; 130:14910 14911. [PubMed: 18922002]

37. Leftwich TR, Madachik MR, Teplyakov AV. Dehydrative Cylocondensation Reactions on Hydrogen-Terminated Si(100) and Si(111): An Ex Situ Tool for the Modification of Semiconductor Surfaces. J. Am. Chem. Soc. 2008; 130:16216-16223. [PubMed: 18989960]

38. Perrine KA, Leftwich TR, Weiland C, Madachik MR, Opila RL, Teplyakov AV. Reactions of Aromatic Bifunctional Molecules on Silicon Surfaces: Nitrosobenzene and Nitrobenzene. J. Phys. Chem. C. 2009; 113:6643-6653.

39. Amy SR, Michalak DJ, Chabal aYJ, Wielunski L, Hurley PT, Lewis NS. Investigation of the Reactions During Alkylation of Chlorine-Terminated Silicon (111) Surfaces. J. Phys. Chem. C. 2007; 111:13053-13061.

40. Seo J, Kim HJ, Pekarek RT, Rose MJ. Hybrid Organic/Inorganic Band-Edge Modulation of $P$ $\mathrm{Si}(111)$ Photoelectrodes: Effects of R, Metal Oxide, and Pt on $\mathrm{H}_{2}$ Generation. J. Am. Chem. Soc. 2015; 137:3173-3176. [PubMed: 25716423]

41. Holubováa B, Cílováa ZZ, Kucerová I, Zlámal M. Weatherability of Hybrid Organic-Inorganic Silica Protective Coatings on Glass. Prog. Org. Coat. 2015; 88:172-180.

42. Kern W. The Evolution of Silicon Wafer Cleaning Technology. J. Electrochem. Soc. 1990; 137:1887-1892.

43. Chabal YJ. Infrared Spectroscopy of Semiconductor Surfaces: H-Terminated Silicon Surfaces. J. Mol. Struct. 1993; 292:65-80.

44. Chabal YJ, Harris AL, Raghavachari K, Tully JC. Infrared Spectroscopy of H-Terminated Silicon Surfaces. Int. J. Mod. Phys. B. 1993; 07:1031-1078.

45. Haber JA, Lewis NS. Infrared and X-Ray Photoelectron Spectroscopic Studies of the Reactions of Hydrogen-Terminated Crystalline $\mathrm{Si}(111)$ and $\mathrm{Si}(100)$ Surfaces with $\mathrm{Br} 2$, I2, and Ferrocenium in Alcohol Solvents. J. Phys. Chem. B. 2002; 106:3639-3656.

46. Gammon WJ, Kraft O, Reilly AC, Holloway BC. Experimental Comparison of N(1s) X-Ray Photoelectron Spectroscopy Binding Energies of Hard and Elastic Amorphous Carbon Nitride Films with Reference Organic Compounds. Carbon. 2003; 41:1917-1923.

47. Tan X, Fan Q, Wang X, Grambow B. Eu(III) Sorption to TiO2 (Anatase and Rutile): Batch, XPS., EXAFS Studies. Environ. Sci. Technol. 2009; 43:3115-3121. [PubMed: 19534122]

48. Briggs, D.; Seah, MP. Practical Surface Analysis. 2nd. Vol. 1. New York: Wiley; 1990.

49. Frisch, MJ.; Trucks, GW.; Schlegel, HB.; Scuseria, GE.; Robb, MA.; Cheeseman, JR.; Scalmani, G.; Barone, V.; Mennucci, B.; Petersson, GA., et al. Gaussian 09, Revision B.01. Wallingford, CT: Gaussian, Inc.; 2009.

50. Krishnan R, Binkley JS, Seeger R, Pople JA. Self-Consistent Molecular Orbital Methods. XX. A Basis Set for Correlated Wavefunctions. J. Chem. Phys. 1980; 72:650-654.

51. Lee CT, Yang WT, Parr RG. Development of the Colle-Salvetti Correlation-Energy Formula into a Functional of the Electron Density. Phys. Rev. B: Condens. Matter Mater. Phys. 1988; 37:785789.

52. Becke AD. A New Mixing of Hartree-Fock and Local Density Functional Theories. J. Chem. Phys. 1993; 98:1372-1377.

53. McLean AD, Chandler GS. Contracted Gaussian Basis Sets for Molecular Calculations. I. Second Row Atoms, Z = 11-18. J. Chem. Phys. 1980; 72:5639-5648.

54. Giesbers M, Marcelis ATM, Zuilhof H. Simulation of XPS C 1s Spectra of Organic Monolayers by Quantum Chemical Methods. Langmuir. 2013; 29:4782-4788. [PubMed: 23548381] 
55. Tao F, Wang ZH, Lai YH, Xu GQ. Attachment of Styrene and Phenylacetylene on Si(111)-7 × 7: The Influence of Substitution Groups on the Reaction Mechanism and Formation of $\pi$-Conjugated Skeletons. J. Am. Chem. Soc. 2003; 125:6687-6696. [PubMed: 12769578]

56. Rodríguez-Reyes JCF, Teplyakov AV. Chemistry of Diffusion Barrier Film Formation: Adsorption and Dissociation of Tetrakis(Dimethylamino)Titanium on Si(100)-2 $\times 1$. J. Phys. Chem. C. 2007; 111:4800-4808.

57. Mui C, Wang GT, Bent SF, Musgrave CB. Reactions of Methylamines at the $\operatorname{Si}(100)-2 \times 1$ Surface. J. Chem. Phys. 2001; 114:10170-10180.

58. Schwartz MP, Hamers RJ. The Role of Pi-Conjugation in Attachment of Organic Molecules to the Silicon (001) Surface. Surf. Sci. 2002; 515:75-86.

59. Ellison MD, Hamers RJ. Adsorption of Phenyl Isothiocyanate on Si(001): A 1,2-Dipolar Surface Addition Reaction. J. Phys. Chem. B. 1999; 103:6243-6251.

60. Harada Y, Koitaya T, Mukai K, Yoshimoto S, Yoshinobu J. Spectroscopic Characterization and Transport Properties of Aromatic Monolayers Covalently Attached to Si(111) Surfaces. J. Phys. Chem. C. 2013; 117:7497-7505.

61. Costa G, Camus A, Gatti L, Marsich N. On Phenylcopper. J. Organomet. Chem. 1966; 5:568-572.

62. Xi M, Bent BE. Iodobenzene on $\mathrm{Cu}(111)$ : Formation and Coupling of Adsorbed Phenyl Groups. Surf. Sci. 1992; 278:19-32.

63. Xi M, Yang MX, Jo SK, Bent BE, Stevens P. Benzene Adsorption on Cu(111): Formation of a Stable Bilayer. J. Chem. Phys. 1994; 101:9122-9131.

64. Queeney KT, Weldon MK, Chang JP, Chabal YJ, Gurevich AB, Sapjeta J, Opila RL. Infrared Spectroscopic Analysis of the $\mathrm{Si} / \mathrm{SiO}_{2}$ Interface Structure of Thermally Oxidized Silicon. J. Appl. Phys. 2000; 87:1322-1330.

65. Miller T, Teplyakov AV. Attachment Chemistry of PCBM to a Primary-Amine-Terminated Organic Monolayer on a Si(111) Surface. Langmuir. 2014; 30:5105-5114. [PubMed: 24735094]

66. Zhang X, Teplyakov AV. Adsorption of C60 Buckminster Fullerenes on an 11-Amino-1-UndeceneCovered Si(111) Substrate. Langmuir. 2008; 24:810-820. [PubMed: 18085804]

67. Liu Y, Chen J, Teplyakov AV. Chemical Passivation Processes for Biofunctionalization Schemes on Semiconductors Surfaces. Langmuir. 2012; 28:15521-15528. [PubMed: 23025426]

68. Zhang X, Antonopoulos IH, Kumar S, Chen J, Teplyakov AV. Tuning the Geometry of ShapeRestricted DNA Molecules on the Functionalized Si(111). Appl. Surf. Sci. 2009; 256:815-818.

69. Nemanick EJ, Hurley PT, Webb LJ, Knapp DW, Michalak DJ, Brunschwig BS, Lewis NS. Chemical and Electrical Passivation of Single-Crystal Silicon(100) Surfaces through a Two-Step Chlorination/Alkylation Process. J. Phys. Chem. B. 2006; 110:14770-14778. [PubMed: 16869585]

70. Wittberg TN, Hoenigman JR, Moddeman WE, Cothern CR, Gulett MR. AES and XPS of Silicon Nitride Films of Varying Refractive Indices. J. Vac. Sci. Technol. 1978; 15:348-352. 

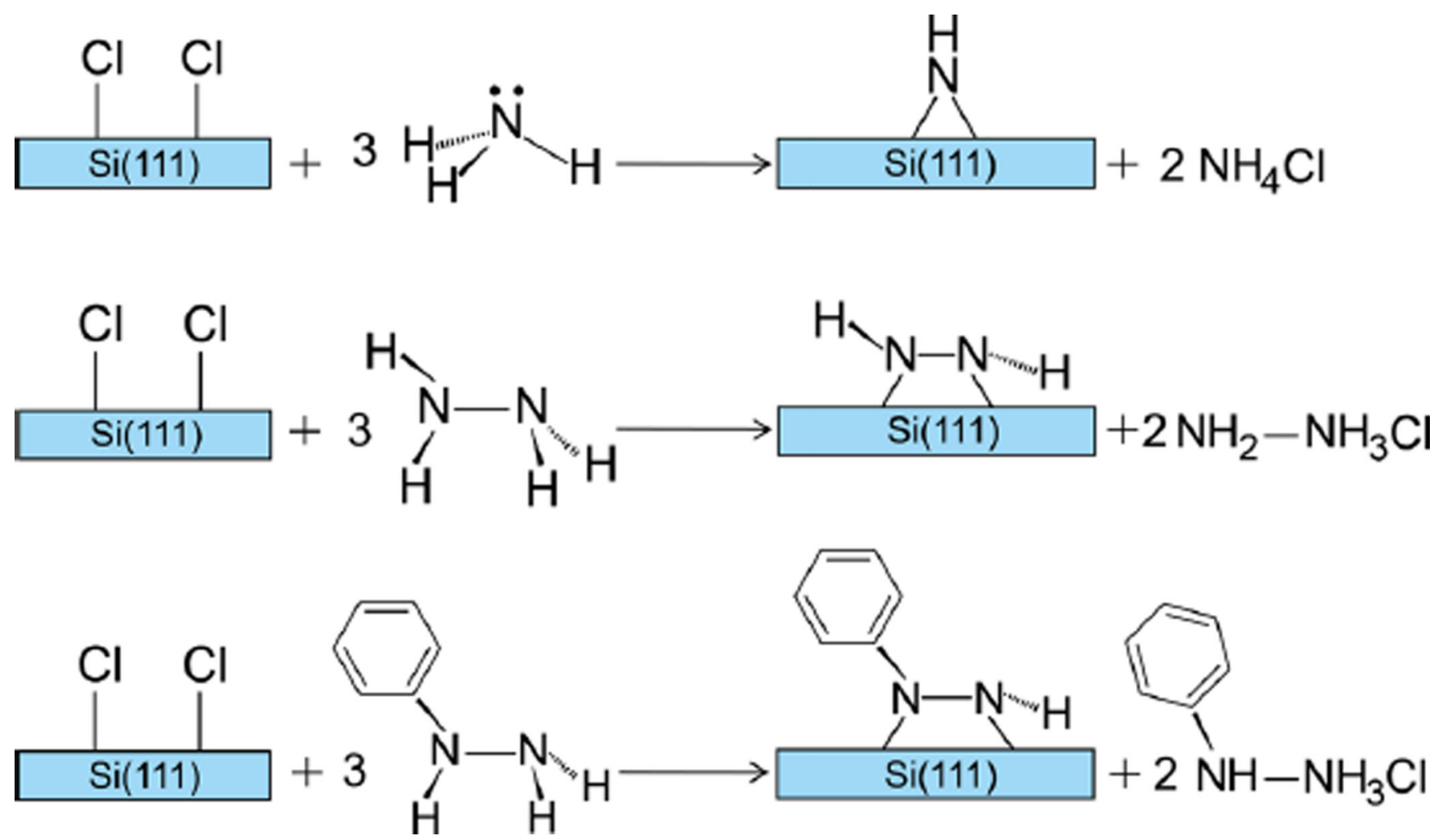

Figure 1.

Schematic comparison of the reactions of $\mathrm{Cl}-\mathrm{Si}(111)$ surface with ammonia, hydrazine, and phenylhydrazine, respectively. The reactions are balanced taking into account the formation of salts in the presence of excess molecular reactants. 


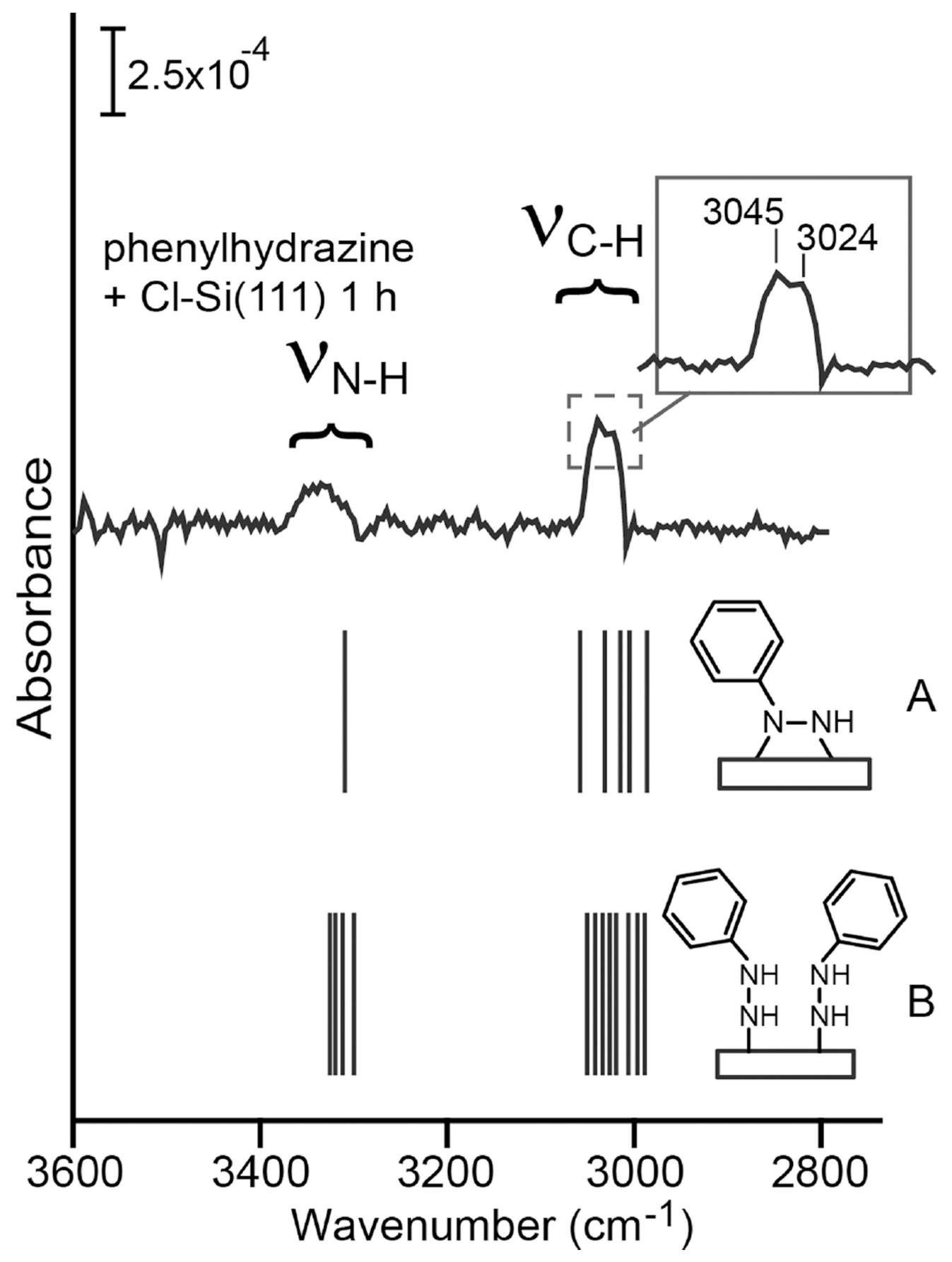

Figure 2.

Summary of the infrared investigations of the $\mathrm{N}-\mathrm{H}$ stretching region and $\mathrm{C}-\mathrm{H}$ stretching region for phenylhydrazine reaction with $\mathrm{Cl}-\mathrm{Si}(111)$ surface. The experimental spectrum is an average of five experiments conducted at identical conditions. The solid bars below the spectrum correspond to the vibrational frequencies predicted computationally for surface species formed, as summarized on corresponding schemes. All predicted frequencies are multiplied by a common scaling factor of 0.965 . 


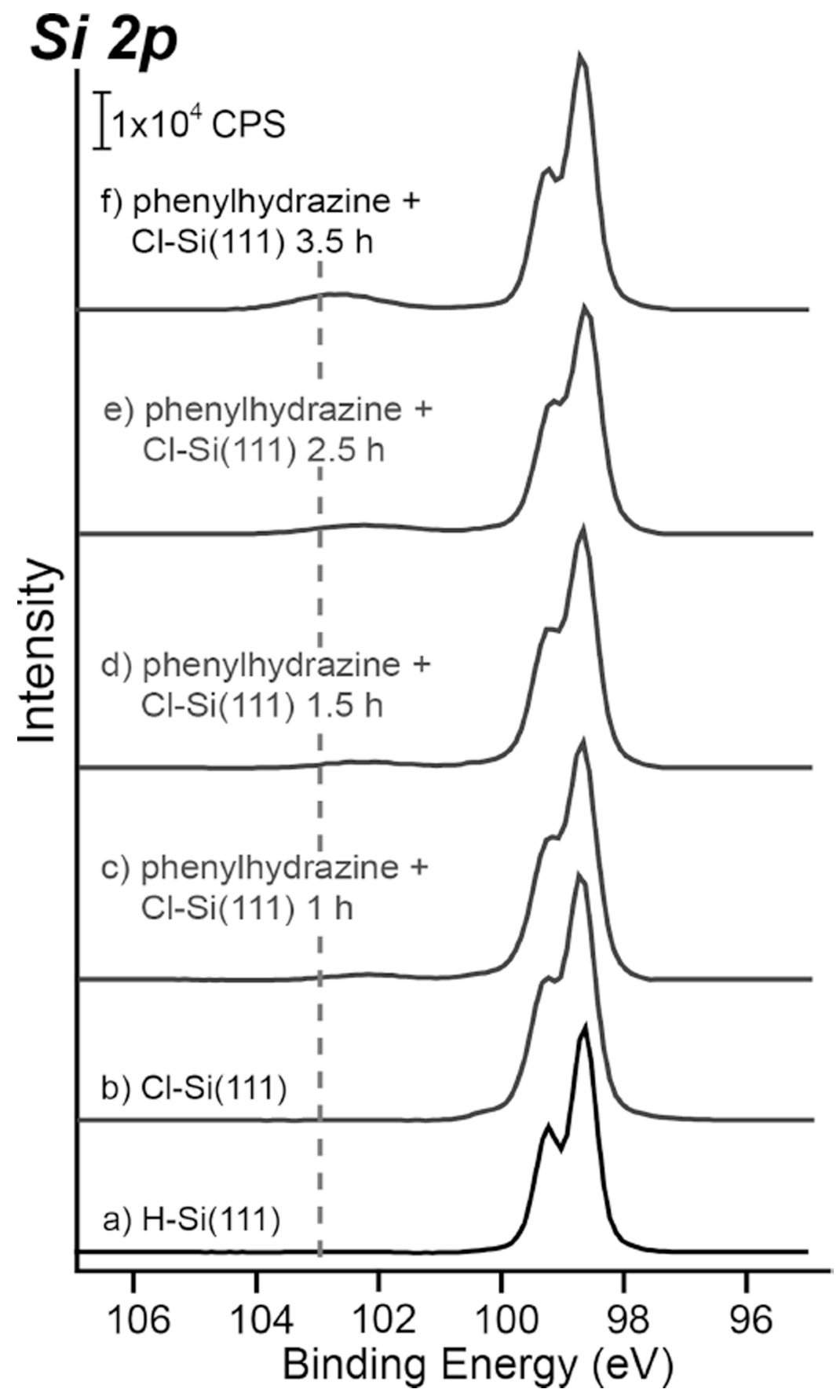

Figure 3.

XPS spectra of the $\mathrm{Si} 2 \mathrm{p}$ region of the $\mathrm{Si}(111)$ surface following the reaction steps: (a) freshly prepared $\mathrm{H}$-terminated $\mathrm{Si}(111)$ surface, (b) freshly prepared $\mathrm{Cl}-\mathrm{Si}(111)$ surface; the surface in (b) reacted with phenylhydrazine for (c) 1 , (d) 1.5 , (e) 2.5 , and (f) $3.5 \mathrm{~h}$. The binding energy corresponding to the formation of $\mathrm{SiO}_{X}$ following surface oxidation is indicated by a dashed line. 


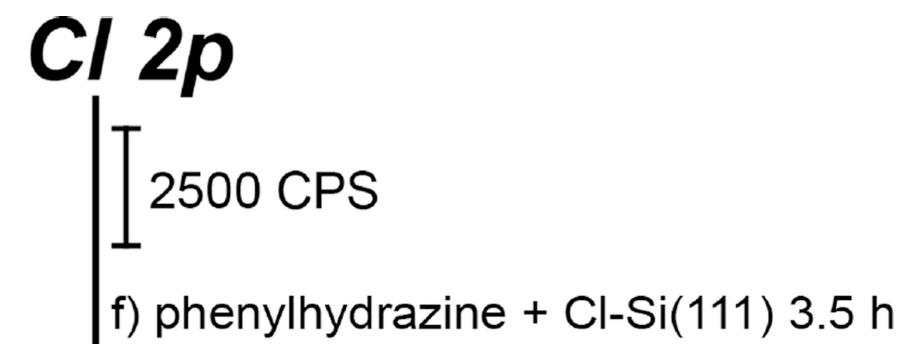

e) phenylhydrazine $+\mathrm{Cl}-\mathrm{Si}(111) 2.5 \mathrm{~h}$

d) phenylhydrazine $+\mathrm{Cl}-\mathrm{Si}(111) 1.5 \mathrm{~h}$

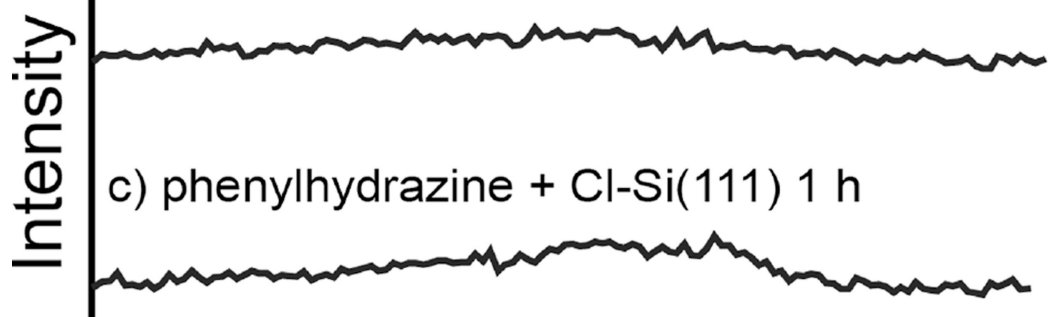

b) $\mathrm{Cl}-\mathrm{Si}(111)$

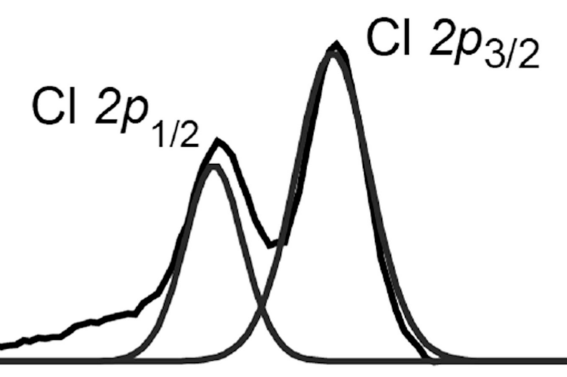

a) $\mathrm{H}-\mathrm{Si}(111)$

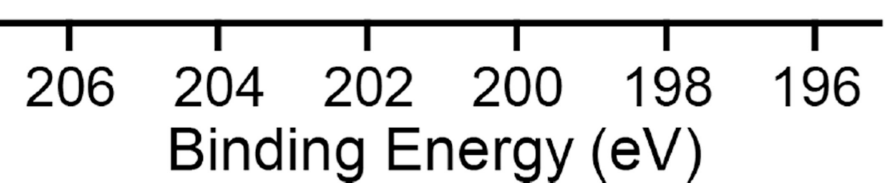

\section{Figure 4.}

XPS spectra of the $\mathrm{Cl} 2 \mathrm{p}$ spectral region for the $\mathrm{Si}(111)$ surface following the reaction of phenylhydrazine with $\mathrm{Cl}-\mathrm{Si}(111)$ surface for (a) freshly prepared H-terminated $\mathrm{Si}(111)$ surface and (b) freshly prepared $\mathrm{Cl}-\mathrm{Si}(111)$ surface; the surface in (b) reacted with phenylhydrazine for (c) 1 , (d) 1.5 , (e) 2.5 , and (f) $3.5 \mathrm{~h}$. 


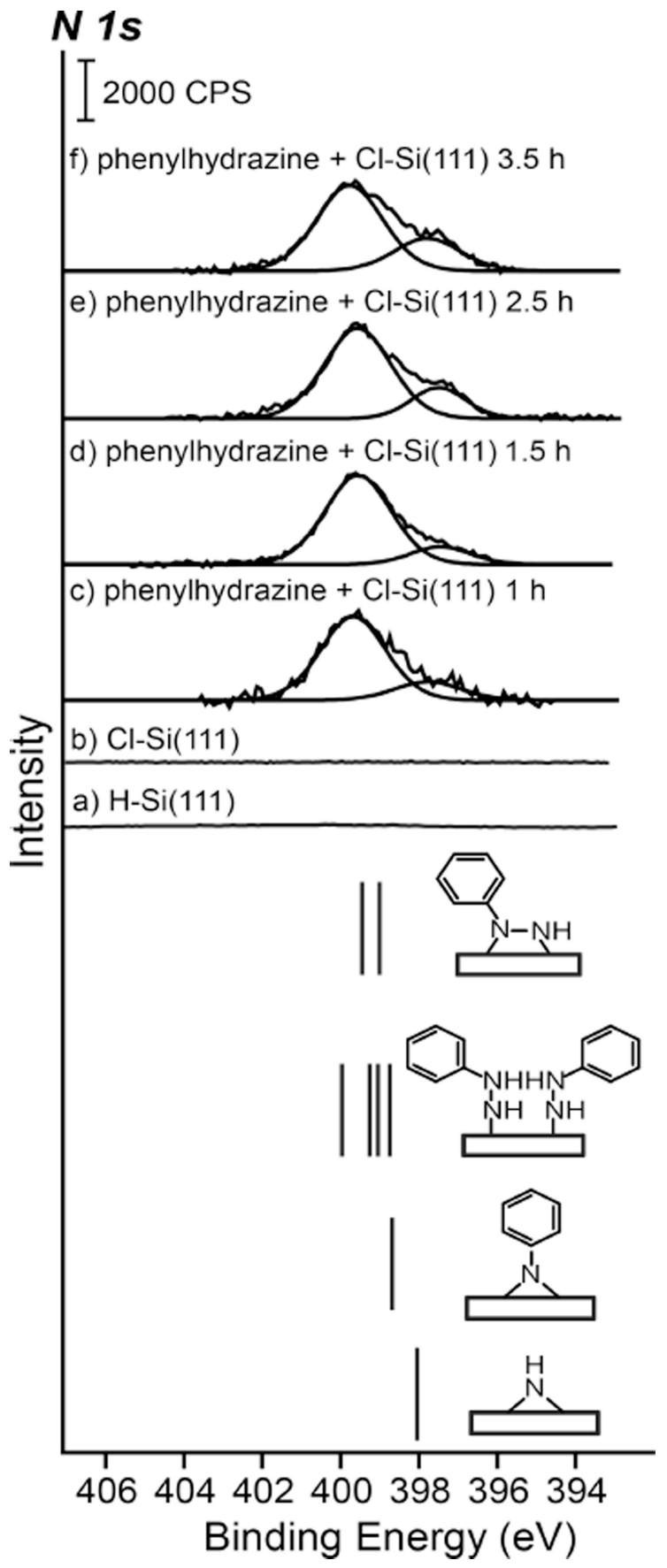

Figure 5.

XPS spectra of the $\mathrm{N}$ 1s spectral region for the $\mathrm{Si}(111)$ surface following the reaction of phenylhydrazine with $\mathrm{Cl}-\mathrm{Si}(111)$ surface for (a) freshly prepared H-terminated $\mathrm{Si}(111)$ surface and (b) freshly prepared $\mathrm{Cl}-\mathrm{Si}(111)$ surface; the surface in (b) reacted with phenylhydrazine for (c) 1, (d) 1.5, (e) 2.5, and (f) $3.5 \mathrm{~h}$. The positions of the expected XPS signatures are computationally predicted based on the previously published calibration procedure $^{12}$ for the model species shown in the figure, which are presented as solid bars underneath the experimental spectra. 


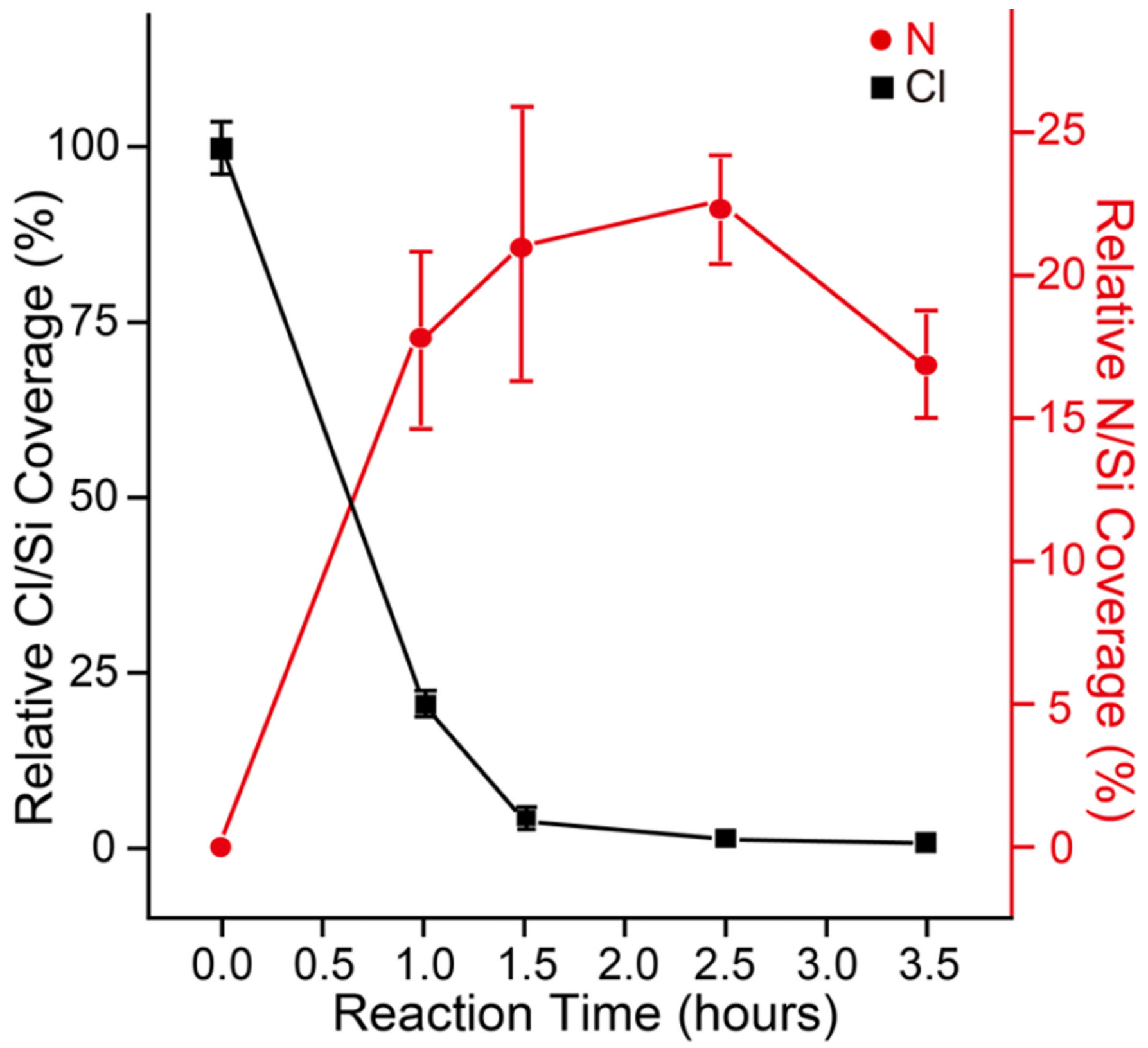

Figure 6.

Summary of the apparent relative coverages of $\mathrm{N}$ and $\mathrm{Cl}$ obtained based on XPS studies as a function of the reaction time between phenylhydrazine and a $\mathrm{Cl}-\mathrm{Si}(111)$ surface. 

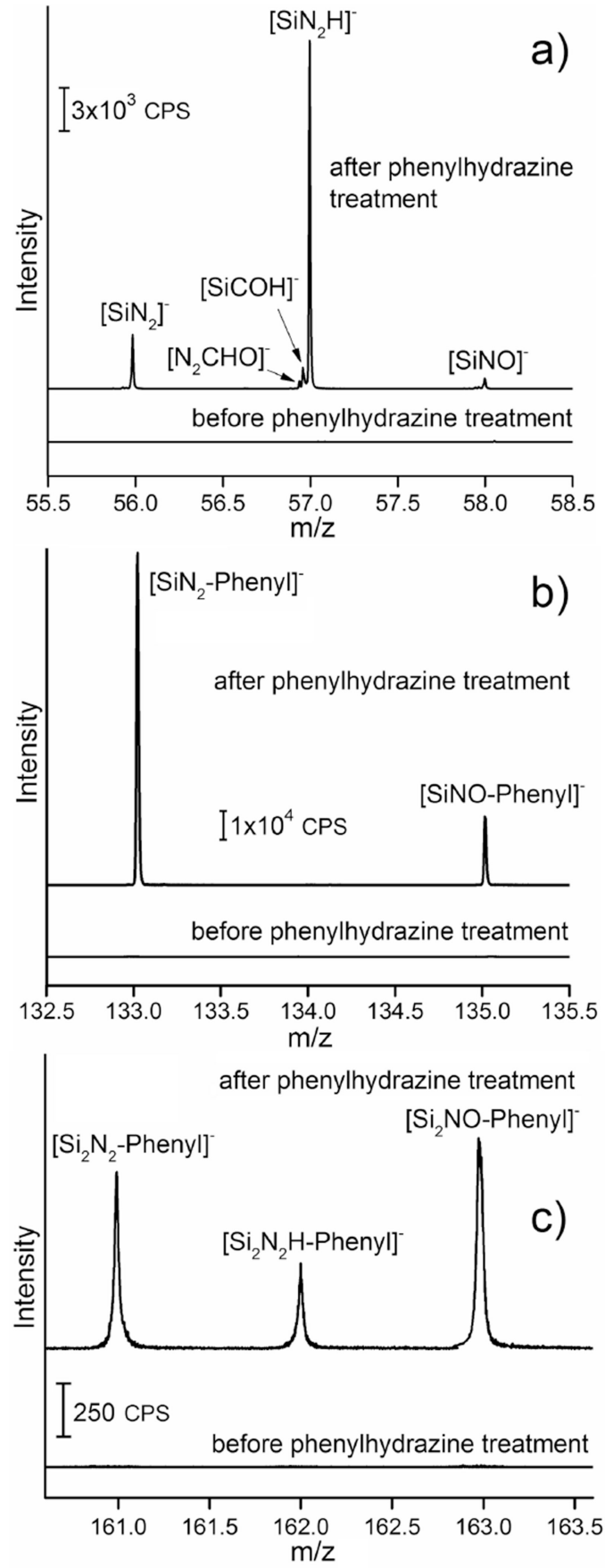

Figure 7.

Negative ion ToF-SIMS spectra of the most informative spectral regions following the reaction of phenylhydrazine with a $\mathrm{Cl}-\mathrm{Si}(111)$ surface: (a) $\left[\mathrm{Si}-\mathrm{N}_{2}\right]^{-}$species $\mathrm{m} / z$ range; (b) [Si- $\mathrm{N}_{2}$-phenyl] ${ }^{-}$species $\mathrm{m} / \mathrm{z}$ range; (c) $\left[\mathrm{Si}_{2}-\mathrm{N}_{2}\right.$-phenyl] ${ }^{-}$species $\mathrm{m} / \mathrm{z}$ range. 


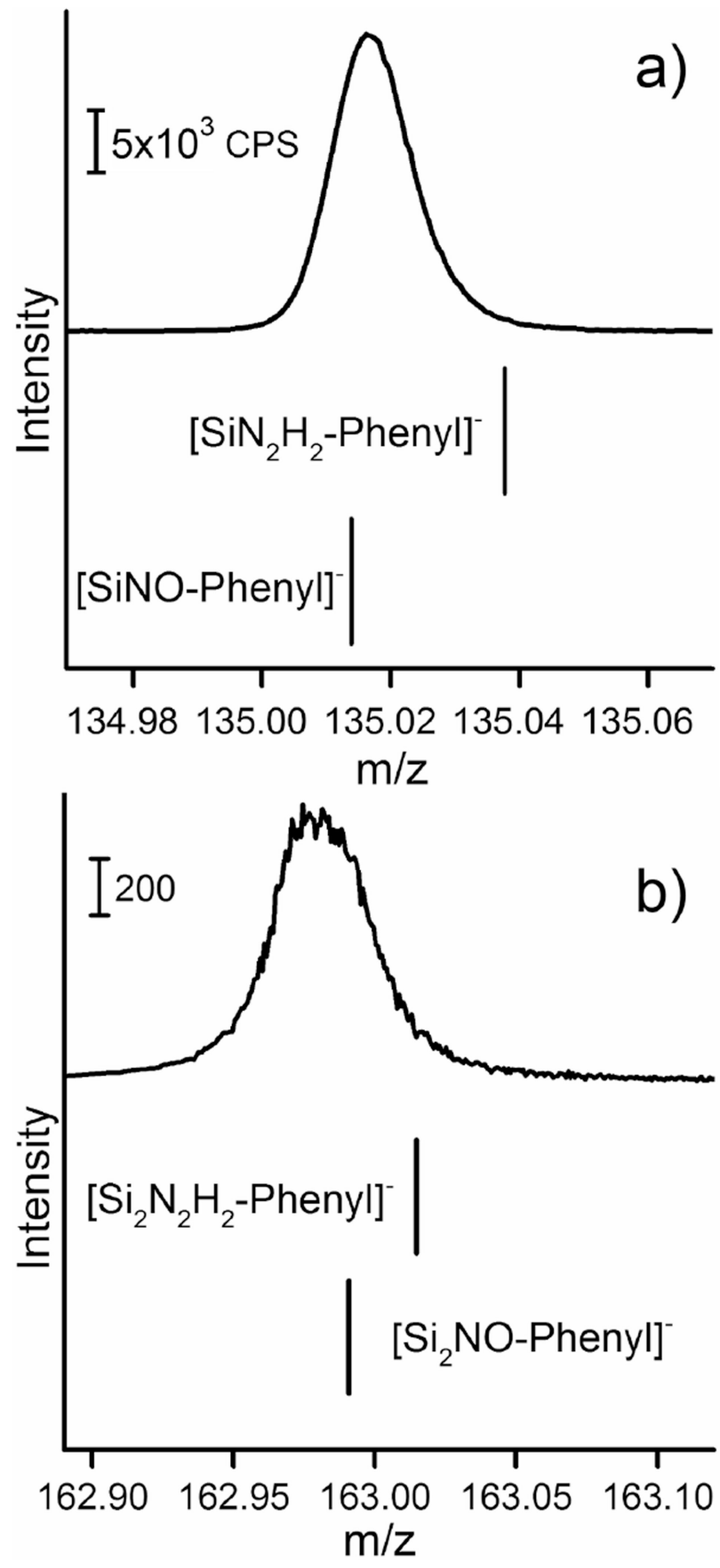

Figure 8.

Negative ion ToF-SIMS spectra of phenylhydrazine treated $\mathrm{Cl}-\mathrm{Si}(111)$ surface: (a) zoom-in of the [Si-NO-phenyl] ${ }^{-}$species $\mathrm{m} / \mathrm{z}$ range; and (b) zoom-in of the $\left[\mathrm{Si}_{2}\right.$-NO-phenyl] ${ }^{-}$species $\mathrm{m} / \mathrm{z}$ range. The exact positions of the ions corresponding to the selected species are indicated by solid vertical lines. 


\section{a)}
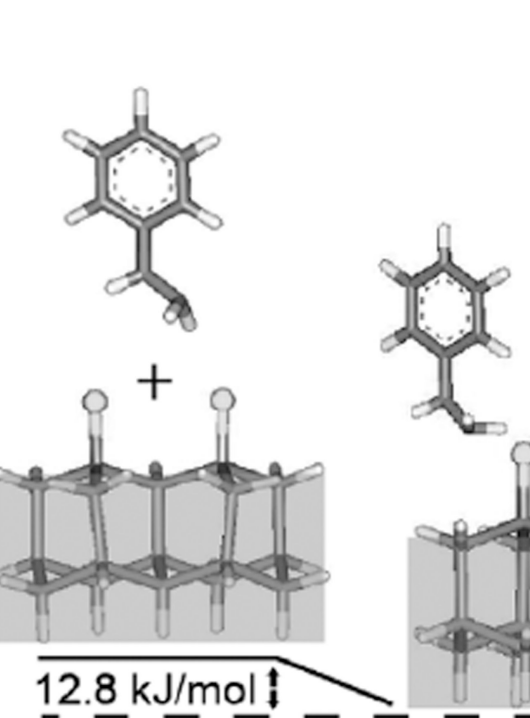

b)

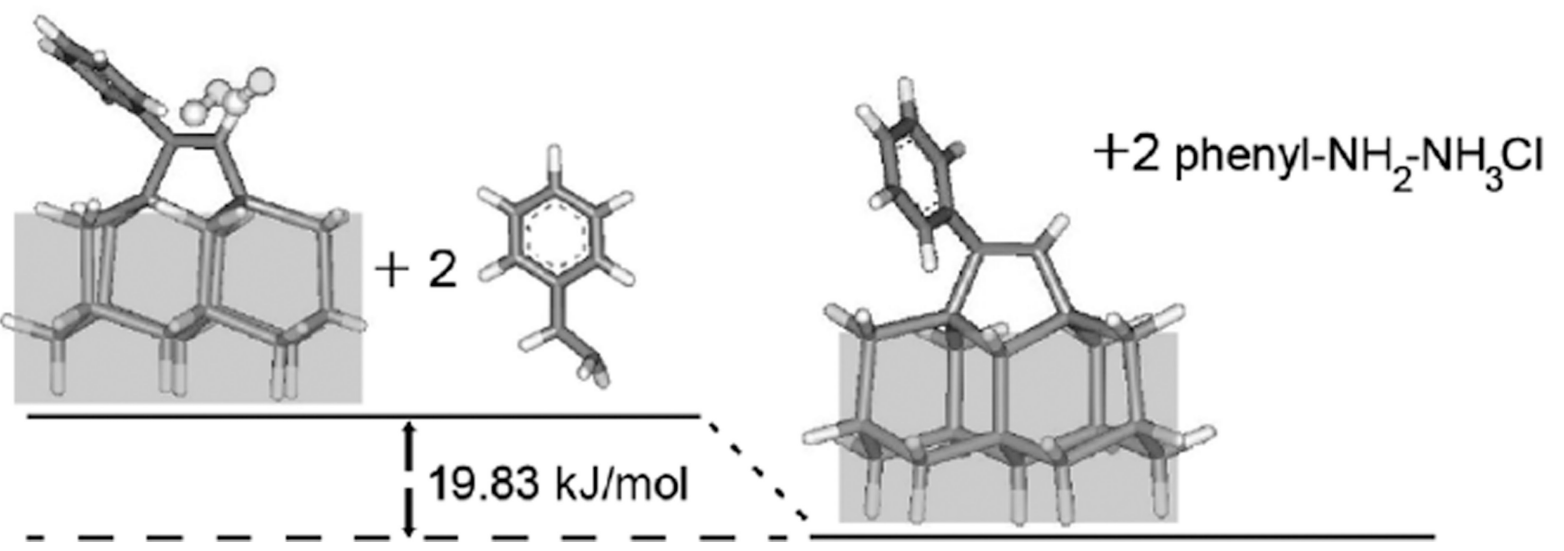

Figure 9.

DFT investigation of the initial steps of a reaction of phenylhydrazine with a $\mathrm{Cl}-\mathrm{Si}(111)$ surface. The proposed mechanism of interaction based on a reaction resulting in a $\mathrm{HCl}$ molecule bound to a surface-attached species as a product (a) is compared with a reaction pathway where the resulting $\mathrm{HCl}$ is bound to another phenylhydrazine molecule (b), which appears in excess in a realistic reaction mixture. Grey - silicon, black - carbon, white hydrogen, blue - nitrogen, yellow - chlorine. Color available online. 


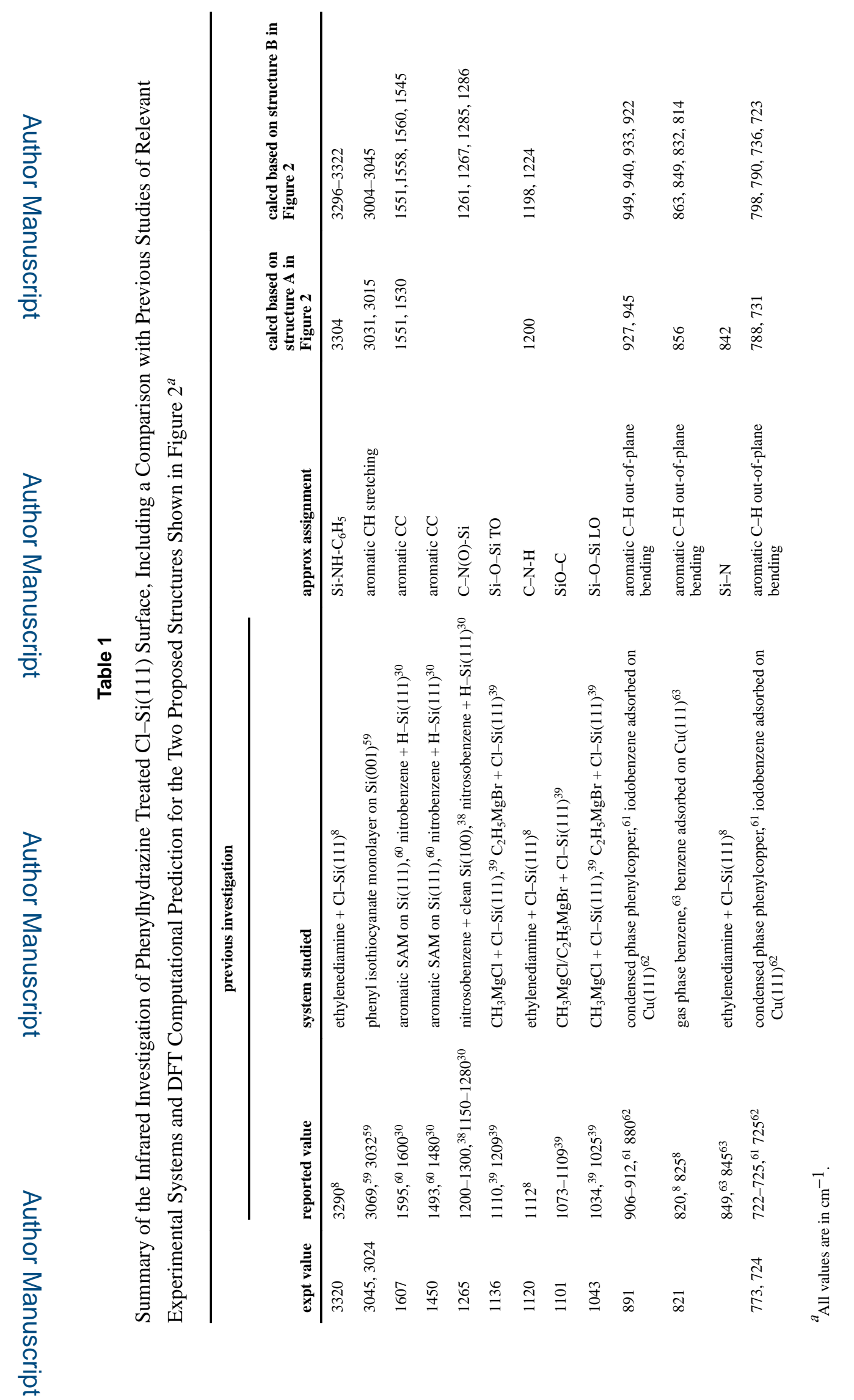

J Phys Chem C Nanomater Interfaces. Author manuscript; available in PMC 2017 May 17. 